\title{
As relações econômicas do esporte com as mudanças sociais e culturais
}

\author{
Elio Carravetta
}

O esporte moderno surge do impulso anglo-saxônico e difunde-se fundamentalmente a partir de 1894, através da restauração dos Jogos Olímpicos e do desenvolvimento da produção industrial. As mudanças sociais e culturais são processos pluralísticos que modificam as pautas das interações estabelecidas. Essas modificações acontecem em função dos bens físicos, procedimentos técnicos e das relações estabelecidas; as causas podem ser tecnológicas, industriais, econômicas, ideológicas ou religiosas.

A sociedade atual converteu o esporte em um setor economicamente dinâmico e atrativo. $\mathrm{O}$ crescente interesse pelo esporte e o desenvolvimento participativo da sociedade em atividades esportivas desencadearam um impacto econômico que incrementa a compra de espetáculos esportivos, serviços, equipamentos, classes, vestimentas, publicidade, patrocínio e outros.

A pluralidade das atividades esportivas desenvolvidas no marco da coletividade social associa o esporte a outros setores da economia. Os recursos privados ou públicos são usados para as construções de parques esportivos, estádios, academias de ginástica, quadras, piscinas, estradas, clubes, hotéis, serviços de bares e restaurantes, alterando de for- ma significativa o paisagismo urbano, ampliando em diferentes segmentos o mercado de trabalho e criando um novo estilo de vida às populações.

Segundo os estudos de C. Ulrich (1975), essas mudanças produzem-se como resultado da difusão ou da invenção. A difusão é o movimento derivado da pauta cultural de uma sociedade até outra ou de um setor até outro dessa mesma sociedade. Os reflexos da difusão cultural são observados no mundo do futebol, que se converteu em um negócio altamente lucrativo em que desfruta de um suporte desproporcionado dos meios de comunicação. A FIFA, que detém o controle do futebol em nível internacional, tem 193 países filiados, entre eles os países da África e da Ásia, que desconheciam a cultura futebolística em décadas passadas e que já manifestam interesses em sediar as próximas Copas Mundiais.

Nos quatro anos entre uma Copa e outra, a FIFA dá treinamento e cursos para mais de 40.000 pessoas, financia 1.270 reuniões para 45 mil técnicos, envolvendo 200 milhões de pessoas em todo o mundo. A FIFA transformou o futebol atual em uma atividade economicamente ativa que movimenta U\$ 225 bilhões por ano e que responde a uma demanda em contínua evolução em que intervém uma 
grande diversidade de atividades empresariais. A invenção revela-se quando existe uma combinação de duas ou mais características culturais, as quais são maiores que a soma das partes totais e servem para uma nova finalidade - não pode ser um processo isolado porque sempre tem um efeito derivado. Manifesta-se nas indústrias de artigos esportivos, que incorporam materiais modernos e recorrem a setores de avançada tecnologia: as novas fibras têxteis são usadas na fabricação de roupas esportivas; os terrenos são construídos com materiais sintéticos que proporcionam grandes mudanças no rendimento e na espetacularidade esportiva; os calçados são fabricados com materiais sintéticos que permitem aumentar a amortização, reduzir o peso e torná-los mais cômodos e eficazes.

Esses processos, segundo G. Murdock (1975), podem ser convenientemente agrupados segundo os termos de inovação, aceitação social, eliminação seletiva e integração. $\mathrm{O}$ câmbio cultural começa com o processo de inovação, que tem como origem os mecanismos psicológicos da aprendizagem, e difere-se dos hábitos puramente individuais pelo fato de chegar a ser socialmente compartido.

Os espetáculos esportivos incrementam os processos de inovação - vertente representativa na relação esporte-economia, responsável pela organização, financiamento e difusão - que têm seus atores, espaços, espectadores, canais de difusão e promotores. Há verdadeiras redes empresariais em crescente desenvolvimento que transformam o esporte em um pólo integrador de tecnologia e em um emissor de novidades.

Os Jogos Olímpicos Modernos, pela sua dimensão mundial (Moragas, 1992), por sua audiência monumental e pelas próprias características do desenvolvimento do acontecimento olímpico, constituem-se em uma área de aplicação e de experimentalidade básica para o desenvolvimento da esponsorização no novo sistema comunicativo moderno. A principal referência econômica da comunicação aos Jogos Olímpicos é a que proporciona a televisão. As grandes empresas (Coca-Cola, IBM,...) são os anunciantes que destinam recursos elevados para atingir os telespectadores dessas manifestações esportivas.
Os Jogos Olímpicos, segundo A. Aguilera (1992), são objeto social em regime de monopólio do Comitê Olímpico Internacional, que atua como uma empresa multinacional em que o risco decorrente do sistema de economia de mercado e de livre empresa praticamente não existe. O Comitê Olímpico Internacional desfruta de todas as vantagens de uma empresa privada sem sofrer seus inconvenientes.

Os atletas são os artífices da espetacularidade esportiva, que se converteram em agentes publicitários das grandes empresas. Marcam um símbolo atrativo da vida moderna, que expressa o êxito e identifica o progresso e, através dos meios de comunicação, fazem do esporte um indutor do consumismo. Com altos salários, os atletas transformaramse em verdadeiros produtos industriais comercializados através dos managers, que constituem uma nova categoria de profissionais incorporada ao mercado de trabalho na área do esporte.

O segundo processo fundamental no câmbio cultural é a aceitação social, que começa com a adoção de um novo hábito por um pequeno número de indivíduos e pode chegar a ser um hábito universal, compartilhado por todos os membros da sociedade. O mecanismo de aprendizagem que desenvolve a aceitação social é o da imitação. $\mathrm{O}$ modelo a partir do qual se copia a conduta forma parte da própria sociedade e não de uma alheia. Os processos de aceitação social são evidenciados nos progressos de igualdade dos direitos das mulheres e na crescente participação destas em atividades de âmbitos esportivos. Os programas esportivos estão experimentando, nos últimos tempos, uma evidente expansão, que se reflete na crescente participação das mulheres em atividades esportivas. Mesmo com essa propagação, ainda se evidenciam demasiadas discriminações em relação à participação das mulheres nas atividades esportivas. Além das normas culturais exercerem uma grande influência no comportamento da mulher em relação à prática do esporte, a discriminação social impede que as mulheres de baixa renda participem de programas esportivos fora do contexto de alguns esportes federados. Essas constatações vêm a reforçar a análise sócio-crítica de P. Boudieu (1988), que reconhece que a participação em atividades físico-esportivas está caracterizada

\section{Os Jogos \\ Olímpicos, segundo $A$. Aguilera (1992), são objeto social em regime de monopólio do Comitê Olímpico Internacional, que atua como uma empresa multinacional em que o risco decorrente do sistema de economia de mercado e de livre empresa praticamente não existe. O Comitê Olímpico Internacional desfruta de todas as vantagens de uma empresa privada sem sofrer seus inconvenientes.}


pela posição que ocupa o indivíduo no espaço social.

A eliminação seletiva constitui o terceiro processo básico de mudança cultural. Toda inovação que foi socialmente aceita entra na competição e sobrevive: à medida que prove ser mais satisfatória que suas alternativas, perdurará como hábito cultural; assim que deixe de proporcionar satisfações semelhantes, diminuirá e finalmente desaparecerá. Podemos constatar, através da concepção de novos produtos, da utilização de novas tecnologias e da adaptação constante do instrumento de produção ao mercado, a origem de novas empresas na área esportiva, que se desenvolveram segundo as formas mais modelares de estratégias em função do binômio produto-

\section{K. Blanchard e \\ A. Cheska \\ (1986) mercado. As relações do esporte e a inovação passam a reger-se pela lógica do mercado e a orientar-se pelas condições de competência e rentabilidade.}

consideram que

a relação do

esporte com

outros processos

sociais é própria

da conservação

cultural.

Com a criação de novas tecnologias, aumentou a rotatividade dos equipamentos esportivos, desencadeando uma busca sistemática por equipamentos mais avançados. Também foram incrementadas novas formas de esportes, os técnico-ecológicos, representados pelo surf, windsurf, asa delta, skateboard, hobbie-cat, esqui, rafting e trekking, que apresentam como características os deslizamentos em distintos meios naturais, ausência de submissão a uma disciplina de equipe muito severa, uma certa distância do corpo e um esforço energético moderado. Em geral, esses tipos de esportes não coincidem com aqueles praticados pelas classes sociais mais populares, em que predominam os jogos esportivos perigosos e esgotadores (ciclismo, futebol, boxe, atletismo, etc).

O quarto e último dos importantes processos de mudança cultural é o da integração. Os hábitos compartilhados que formam uma cultura não somente flutuam em seu grau de aceitação social e competição pela sobrevivência, como também se adaptam progressivamente entre si, pelo fato de que tendem a formar um todo integrado. A valorização do "esporte-prática" por amplos e diversos segmentos da população não impedem que o "esporte-espetáculo" continue a desenvolver e atrair uma maior atenção social, econômica e política.
K. Blanchard e A.Cheska (1986) consideram que a relação do esporte com outros processos sociais é própria da conservação cultural. O esporte contribui para as mudanças culturais através do método que chamam de "inculturação", que se obtém por meio da interação de novos indivíduos às maneiras e aos costumes das sociedades. Quando há um intercâmbio de características ou complexos culturais entre os membros de diferentes sociedades, denominam-no "aculturação".

A aculturação, segundo os trabalhos de M. Canevacci (1991), apresenta atualmente dois aspectos contraditórios: por uma parte, o reconhecimento competitivo da própria identidade cultural frente à homologação crescente; por outra parte, a exigência de um intercâmbio solidário e paritário entre culturas diferentes para sustentar um diálogo cada vez mais aberto. Os diferentes estudos parecem demonstrar que o esporte moderno está convertendo-se em um novo meio de comunicação multinacional e continua em crescente processo de transformação pela sua dimensão internacional, marcada pela sociedade de consumo. E sua adoção pelas sociedades mais elementares parece dar-se de acordo com as correntes ideológicas emanadas dos grupos dominantes e dirigidas para os gupos culturais subordinados, com suas inerentes implicações de desigualdade.

\section{REFERÊNCIAS BIBLIOGRÁFICAS}

AGUILERA, A. Estado y Deporte. Legislación, organización y administración dei deporte. Granada: Comares, 1992.

BLANCHARD, K.; Cheska, A. Antropologia dei deporte. Barcelona: Bellaterra, 1986.

BOURDIEU, P. Cosas dichas (173-184). Barcelona: Gedisa, 1988.

BROHM, J. Sociologia política dei deporte. México: Fondo de Cultura Econômica, 1982.

CANEVACCI, M. La interpretación antropológica dei deporte: una labor del museo. In: Museum, $\mathrm{n}^{\circ} 170$, vol.XLIII, $\mathrm{n}^{\circ}$ 2, (7476), Paris: Unesco, 1991.

GARCIIA FERRANDO, M. Aspectos sociales del deporte: una reflexión sociológica. Madrid: Alianza, 1990.

- Cambio Y permanência en los há bitos deportivos de los espanoles. Re- 
vista de Ciências Sociales, Noviembre, $\mathrm{n}^{\circ}$ 110-111 (p.55-84). Madrid: Sistema, 1988.

KROEBER, (1917). Lo superorgánico (p.4784). In: J.KAHN (comp.). $E l$ concepto de cultura: textos fundamentales. Barcelona: Anagrama, 1975.

MORAGAS, M. Los juegos de la comunicación: las múltiples dimensiones comunicativas de los juegos olímpicos. Madrid: Fundesco, 1992.

MURDOC, G. (1975). Processo dei cambio cultural. In: SHAPIRO, H.(Coord.) Hombre, cultura y sociedad. México: Fondo de Cultura Econômica, 1975.
THOMAS, R., HAUMONT, A.; J.L. LEVET. Sociologia del deporte. Barcelona: Bellaterra, 1988.

ULRICH, C. Fundamentos Sociales de la Educacion Física. Buenos Aires: Paidos, 1975.

\section{UNITERMOS}

Esporte - Economia - Sociedade - Cultura

* Elio Carravetta é Professor Adjunto da Universidade Federal do Rio Grande do Sul e Doutor em Educação Física. 